\title{
Identificação de Micro-Organismos em Leite de Vacas da Zona da Mata de Pernambuco e Avaliação da Atividade Antioxidante e Antibacteriana de Peptídeos Produzidos A Partir da Hidrólise Enzimática Desse Leite.
}

Roberta Carolline de Oliveira Silva (I), Renata Rafaella de Moraes Cordeiro (I), Marcela Araújo Pereira (I), Thiago Véras Cavalcanti Firmino (I), Roberto Afonso da Silva (I), Isabella Macário Ferro Cavalcanti (I)

(I) UFPE - Universidade Federal de Pernambuco (Rua Alto do Reservatório, S/N - Bela Vista, Vitória de Santo Antão-PE)

\section{Resumo}

Introdução: Os alimentos em geral podem apresentar um conjunto de micro-organismos próprios que normalmente surgem dos processos de produção, armazenamento e processamento. O leite é uma fonte rica de proteínas que apresentam várias sequências de aminoácidos com propriedades bioativas. Desta forma, o presente estudo tem como objetivo identificar micro-organismos contaminantes em leite de vacas da Zona da Mata de Pernambuco e avaliar a atividade antioxidante e antibacteriana de peptídeos produzidos a partir da hidrólise enzimática desse leite. Material e Métodos: Amostras de leite de vaca foram coletadas em propriedades da Zona da Mata de Pernambuco e encaminhadas em caixas isotérmicas para o Laboratório de Microbiologia e Imunologia do Centro Acadêmico de Vitória da Universidade Federal de Pernambuco. Posteriormente, foram quantificados e identificados bolores e leveduras (DRBC), assim como micro-organismos aeróbios mesófilos (PCA) e fungos produtores de aflatoxinas (AFPA) nas amostras coletadas. Diluições das amostras foram plaqueadas nos meios de cultura acima citados e após incubação as

\footnotetext{
Referência:

Roberta Carolline de Oliveira Silva (I), Renata Rafaella de Moraes Cordeiro (I), Marcela Araújo Pereira (I), Thiago Véras Cavalcanti Firmino (I), Roberto Afonso da Silva (I), Isabella Macário Ferro Cavalcanti (I). Identificação de MicroOrganismos em Leite de Vacas da Zona da Mata de Pernambuco e Avaliação da Atividade Antioxidante e Antibacteriana de Peptídeos Produzidos A Partir da Hidrólise Enzimática Desse Leite.. In: Anais do 12 Congresso Latinoamericano de Microbiologia e Higiene de Alimentos - MICROAL 2014 [= Blucher Food Science Proceedings, num.1, vol.1]. São Paulo: Editora Blucher, 2014. DOI 10.5151/foodsci-microal-181
} 
colônias foram contadas e identificadas. A hidrólise do leite foi realizada utilizando tripsina e os hidrolisados obtidos foram liofilizados. A atividade antioxidante foi determinada utilizando o método do 2,2-azinobis (ácido 3etilbenzotiazolina-6-sulfonico (ABTS) e a avaliação da atividade antibacteriana foi realizada pelo método da microdiluição de acordo com Clinical and Laboratory Standards Institute (CLSI). Resultados e Discussão: Nas 22 amostras de leite de vaca coletadas a contagem de micro-organismos aeróbios mesófilos foi 145,4 \pm 37,2 UFC/mL (cocos Gram positivos, bacilos Gram negativos e leveduras), os fungos estavam na concentração de 8,5 $\pm 2,4 \mathrm{UFC} / \mathrm{mL}$ (leveduras e fungos filamentosos), mas nenhuma das amostras apresentou fungos produtores de aflatoxinas. Os peptídeos obtidos não apresentaram atividade antibacteriana frente a 10 isolados clínicos de Staphylococcus aureus resistente a meticilina (MRSA) na faixa de concentração de 1 a $250 \mu \mathrm{g} / \mathrm{mL}$, porém os peptídeos apresentaram atividade antioxidante na faixa de 1400 a $1600 \mu \mathrm{M}$ de TEAC. Conclusão: Após análise dos resultados podemos sugerir que os peptídeos do leite podem apresentar atividade biológica, especialmente a atividade antioxidante, podendo assim ser incorporados em novos suplementos dietéticos.

Palavras-Chave: Leite, Micro-organismos, Atividade antioxidante, Atividade antibacteriana

Agência de Fomento: FACEPE 